\title{
Taxas longitudinais de retenção e evasão: uma metodologia para estudo da trajetória dos estudantes na educação superior
}

\author{
Paulo Lima Junior ${ }^{a}$ \\ Cynthia Bisinoto ${ }^{b}$ \\ Nilce Santos de Melo ${ }^{c}$ \\ Mauro Rabelo ${ }^{d}$
}

\section{Resumo}

Com a expansão do sistema federal de educação superior, a evasão e a retenção têm sido redescobertas pela pesquisa educacional. Neste artigo, avaliam-se criticamente as taxas empregadas pelo Ministério da Educação (MEC) e Tribunal de Contas da União (TCU) para controle e acompanhamento da trajetória dos alunos nas universidades brasileiras. Partindo dessa crítica, são propostos indicadores alternativos para quantificar a evasão e a retenção: a taxa longitudinal de evasão (TLE) e a taxa longitudinal de retenção (TLR). Esses indicadores foram testados com dados extraídos do registro acadêmico da Universidade de Brasília (UnB). Os resultados dessa instituição indicam, progressivamente, aumento da evasão e redução da retenção. Essas transformações podem estar relacionadas ao próprio processo de expansão do sistema educacional.

Palavras-chave: Evasão. Retenção. Educação superior.

\section{Introdução}

A democratização do acesso à educação superior, com a garantia de manutenção da qualidade, é um dos compromissos do Estado brasileiro, expressamente citado na meta 12 do Plano Nacional de Educação (BRASIL, 2014). Atingir essa meta

\footnotetext{
a Universidade de Brasília, Brasília, DF, Brasil.

b Universidade de Brasília, Brasília, DF, Brasil.

c Universidade de Brasília, Brasília, DF, Brasil.

d Universidade de Brasília, Brasília, DF, Brasil.

Recebido em: 25 set. 2017

Aceito em: 26 out. 2018
} 
significa elevar a taxa bruta de matrícula na educação superior para $50 \%$ (cinquenta por cento) e a taxa líquida para $33 \%$ (trinta e três por cento) da população de 18 (dezoito) a 24 (vinte e quatro) anos de idade, asseguradas a qualidade da oferta e a expansão para, pelo menos, $40 \%$ (quarenta por cento) das novas matrículas, no segmento público. Hoje, a cada 4 (quatro) estudantes matriculados na educação superior brasileira, apenas 1 (um) frequenta uma instituição pública.

Sem dúvida, o acesso à educação superior ampliou-se muito no Brasil, mas ainda em patamares insuficientes para cumprir a meta definida no Plano Nacional de Educação (PNE 2014-2024) ou para alcançar as taxas dos países desenvolvidos, ou mesmo para igualar o país à grande parte de seus países vizinhos (LÓPEZ SEGRERA, 2016). O aumento da participação dos jovens na educação superior é crucial para estimular a inovação, garantir os níveis adequados de produção de bens e serviços especializados e favorecer a promoção da justiça social. No entanto, o ingresso, de per si, não garante todo esse ganho se não vier acompanhado das condições que contribuam para a permanência dos estudantes, do ingresso à formatura. É nesse contexto que a compreensão aprofundada da evasão e retenção se torna peça-chave no intricado painel de fenômenos que cercam a educação superior.

Neste artigo, serão discutidas as possibilidades e limitações dos indicadores mais empregados pelo Ministério da Educação (MEC) e pelo Tribunal de Contas da União (TCU) para o monitoramento da trajetória discente, a saber: a Taxa de Conclusão dos Cursos de Graduação (TCG) e a Taxa de Sucesso na Graduação (TSG). Partindo dessa análise, serão apresentados dois indicadores alternativos, de caráter longitudinal, para acompanhar as trajetórias dos estudantes de graduação, aqui denominados de Taxa Longitudinal de Evasão (TLE) e Taxa Longitudinal de Retenção (TLR). Esses indicadores foram testados com dados extraídos do registro acadêmico dos estudantes da Universidade de Brasília (UnB). Nesse contexto, esta pesquisa é norteada pela seguinte pergunta: de que maneira a TLE e a TLR podem contribuir para a compreensão das trajetórias discentes nos cursos de graduação?

\section{Evasão, retenção e expansão da educação superior}

Evasão, do latim evaš̆o, significa fugir deliberadamente. Segundo a Comissão Especial de Estudos sobre a Evasão nas Universidades Brasileiras (ANDIFES, 1996), é possível distinguir três tipos de evasão: (1) do curso, (2) da instituição; (3) do sistema. Essa distinção é importante porque o abandono do curso sem abandono da instituição ou do sistema pode ser considerado um caso de mobilidade. 
Analisando historicamente o processo da evasão na educação superior, Baggi e Lopes (2011) e Lima (2013) e contextualizaram as mudanças neste nível educativo no Brasil, a partir da década de 1990, com a expansão das IES nas diversas áreas de ensino. Entre as conclusões, os autores destacaram que houve significativo aumento de alunos na educação superior pós anos 1990, mas, ao mesmo tempo, foi perceptível o grande número de alunos evadidos. Dados do Censo da Educação Superior mostram que, apesar da expansão, a quantidade total de alunos formados em algumas modalidades caiu nos anos 2012 e 2013. No universo dos cursos de graduação, as licenciaturas parecem ter sido as mais atingidas, formando, em 2013, 15,4\% pessoas a menos que em 2011, apesar do aumento da quantidade de vagas oferecidas nos anos anteriores ( INEP, 2015). Esse dado indica que, durante o processo de expansão, a evasão pode ter aumentado em alguns setores da educação superior sem, contudo, atingir todos os cursos da mesma maneira.

No que tange à evasão acadêmica, um conjunto diverso de investigações, no Brasil e no mundo, tem buscado compreendê-la (FERRAO; ALMEIDA, 2018; PRESTES; FIALHO, 2018), sendo que os estudos variam em termos de sua finalidade: determinar as razões que levam os estudantes a abandonar o curso superior segundo suas percepções; identificar os fatores que permitem a permanência deles; elaborar sistemas de previsão que permitam identificar os alunos em risco de abandono; e avaliar a eficácia das ações voltadas para a prevenção e promoção da permanência e conclusão (ALFA-GUIA, 2013).

Retenção, do latim retentǐo, no contexto da Educação Superior, pode se referir ao tempo adicional que o estudante leva para completar a formação superior, tomando como referência o tempo de conclusão institucionalmente previsto. Nesse sentido, considera-se retido aquele aluno que, apesar de esgotado o prazo de integralização curricular fixado, ainda não concluiu o curso, mantendo-se matriculado na instituição (ANDIFES, 1996). Partindo do entendimento de que apenas as informações estatísticas não são suficientes para compreender a complexidade desse fenômeno, alguns estudos têm sido realizados com o objetivo de identificar e analisar seus principais fatores (APPIO et al., 2016; SILVA; RODRIGUES; BRITO, 2014). Esses autores apontam que os fatores intervenientes no processo de retenção incluem a descontinuidade entre as realidades vivenciadas no ensino médio e no superior, o desempenho em disciplinas e o número de reprovações, o trancamento de curso, a transferência para outro curso na própria instituição (mobilidade interna), o desafio de conciliar atividades acadêmicas, profissionais e familiares, a frágil integração social e acadêmica à instituição, a realização concomitante de outro curso superior, entre outros. 
Evasão e retenção não são fenômenos recentes, mas ganharam projeção e importância em razão do processo de expansão da educação superior ocorrido nas últimas décadas. Em linhas gerais, a educação superior está associada à ampliação da escolarização da população, à inclusão socioeconômica, à crescente qualificação profissional e ampliação da empregabilidade, bem como à redução das assimetrias sociais. A esse respeito, a Conferência Mundial de Ensino Superior (UNESCO, 2009a) ressaltou que "nunca foi tão importante investir na educação superior como força maior na construção de uma sociedade inclusiva e de conhecimento diversificado, além de avançar em pesquisa, inovação e criatividade" (p. 2).

Nas economias desenvolvidas e em desenvolvimento, os sistemas de educação superior têm se expandido de forma acentuada, acolhendo públicos não tradicionais e impulsionando uma significativa transformação no perfil estudantil (OCDE, 2014; 2016; UNESCO, 1998; 2009b). No cenário mundial, o número de estudantes matriculados na educação superior cresceu de 28,6 milhões em 1970 para 152,5 milhões em 2007, sendo que o crescimento mais intenso ocorreu a partir dos anos 2000 (UNESCO, 2009a). Seguindo a tendência mundial, a educação superior no Brasil vem se expandindo de modo acelerado desde a segunda metade da década de 1990, com o predomínio de instituições privadas de pequeno porte (SEGENREICH; CASTANHEIRA, 2009).

Na direção de modificar essa realidade nacional em que predominam IES privadas e de pequeno porte, especialmente a partir de 2007 foi promovida a criação de novas universidades e a expansão dos campi das instituições federais de ensino superior (IFES). Enquanto em 2000 existiam 39 universidades federais; em 2010 esse número saltou para 58 instituições, ou seja, houve um crescimento de 48,7\% ( INEP, 2015). O principal impulso para esse crescimento foi dado pelo Programa de Apoio a Planos de Reestruturação e Expansão das Universidades Federais Brasileiras (REUNI), instituído pelo Decreto nº 6.096 (BRASIL, 1997), que tinha como objetivo principal criar condições para a ampliação do acesso e permanência na graduação. A expansão induzida pelo REUNI não foi suficiente para alterar o predomínio da iniciativa privada na educação superior brasileira. Por outro lado, ainda que relativamente modesta, a expansão do sistema federal tem contribuído para renovar a preocupação com a trajetória dos alunos nas universidades federais (GILIOLI, 2016).

\section{Taxas de Sucesso e de Conclusão da Graduação}

Na perspectiva da otimização no uso dos recursos públicos e coadunando-se ao pensamento da administração gerencial das IES, um conjunto de indicadores de 
gestão e de avaliação das universidades têm sido propostos e implementados em diferentes países (ANDRIOLA; ARAÚJO, 2018; BIGGERI; BINI, 2001; DUNDAR; LEWIS, 1999; YONEZAWA, 2008). No Brasil, especificamente nos casos das IFES, estão em vigência os indicadores de desempenho da gestão propostos pelo TCU em conjunto com a Secretaria Federal de Controle Interno e a Secretaria de Educação Superior (SESu) do Ministério da Educação (BRASIL, 2005), entre os quais se destaca Taxa de Sucesso na Graduação (TSG).

Por definição, a TSG é obtida pela razão entre o número de diplomados e o número de ingressantes, ajustados pelo ano em que esses alunos ingressaram na instituição e por um tempo de permanência $k$ fixado pela SESu/MEC para cada curso ( BRASIL, 2005):

$$
T S G(n)=\frac{\text { quantidade de diplomados no ano } n}{\text { quantidade de ingressantes no ano } n-k},
$$

em que $n$ é o ano de exercício e $k=4,5$ ou 6 é o tempo previsto de duração do curso.

Para o cálculo da "Quantidade de ingressantes no ano $n-k$ ", deve ser considerado o ano do ingresso dos estudantes que se graduam no ano de exercício $n$, com base na duração padrão prevista para cada curso. Por exemplo, para cursos com duração de 4 anos, deve ser considerado o número de ingressantes quatro anos letivos antes do ano de exercício para o qual se deseja calcular a TSG. Desse modo, a TSG leva em consideração o tempo previsto para a conclusão de cada curso, seja de 4, 5 ou 6 anos. De forma inversa, este indicador tenta apresentar o grau de evasão dos alunos que ingressam em cada IFES. O Gráfico 1 apresenta a evolução dos valores assumidos pela TSG na UnB comparada à média das demais IFES. A leitura inicial desse gráfico poderia levar à conclusão de que a eficiência global do sistema federal caiu progressivamente nos anos seguintes à expansão (entre 2009 e 2014, a TSG média das IFES caiu de $60 \%$ para $40 \%$ ). Contudo, ainda que a leitura do gráfico seja de queda, é preciso considerar que o valor da TSG tende a cair após a expansão da oferta de vagas mesmo nos casos em que os percentuais de alunos retidos e evadidos forem mantidos constantes. Essa "anomalia" da TSG resulta da maneira como esse indicador está definido e será problematizada nas seções seguintes.

No Gráfico 1, também podemos observar que, enquanto a TSG do sistema federal apresenta uma tendência de queda no período observado, a mesma taxa calculada 
para a UnB apresenta um comportamento diverso. No ano de 2010, ela segue de perto o comportamento nacional; em 2011, cai dez pontos percentuais em relação à tendência nacional; já em 2012, a supera em dez pontos. Observamos que esse comportamento pode ser atribuído ao impacto da greve de 2010 no calendário acadêmico, a mais longa já ocorrida na instituição. Em vista dessa greve, o segundo período letivo de 2011 foi prolongado para o ano de 2012, atrasando as formaturas. Como os dados a partir dos quais a TSG é computada levam em consideração o registro discente ao final do ano-calendário, atrasos nas formaturas fazem com que alguns concluintes sejam computados somente no ano seguinte. Descontando-se esse efeito, percebemos que o comportamento da TSG na UnB segue de perto a tendência do sistema federal.

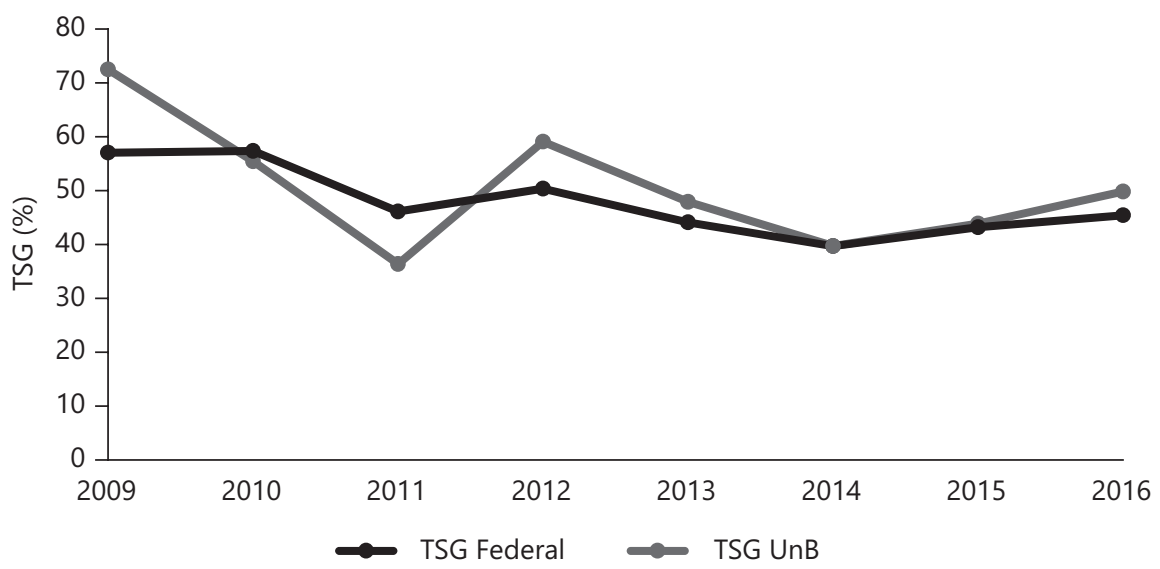

Gráfico 1. Taxa de Sucesso da Graduação (TSG) do sistema Federal e da Universidade de Brasília no período de 2009 a 2016. Fonte: Ministério da Educação (2017).

No Brasil, a chamada Taxa de Conclusão dos Cursos de Graduação (TCG) foi introduzida pelo decreto que cria o REUNI (BRASIL, 2007). Trata-se de um indicador semelhante à TSG que resulta da razão entre formados e ingressantes de cada instituição, estando também relacionado à evasão. Ao calcular a TCG, deveria ser obtida uma medida do sucesso da instituição em formar seus estudantes no tempo previsto. A TCG também pretende contemplar a eficiência com que a universidade preenche as vagas ociosas geradas pela saída de alunos (BRASIL, 2007). Assim, ela condensa, em um único indicador, um conjunto de informações relativas à certificação dos ingressantes no tempo previsto. 
Por definição, a TCG de cada IES é calculada pela razão entre o total de diplomados nos cursos de graduação presenciais, no ano $n$, e o total de vagas oferecidas para ingresso, cinco anos antes:

$$
\operatorname{TSG}(n)=\frac{\text { quantidade de diplomados no ano } n}{\text { quantidade de ingressantes no ano } n-5},
$$

em que $n$ é o ano de exercício.

A TCG tem a vantagem de poder ser calculada a partir de dados públicos disponíveis nas sinopses estatísticas do Censo da Educação Superior (www.inep. gov.br). Percebe-se que se trata de um indicador um pouco mais rudimentar que a TSG, mas apresenta comportamento e significado semelhantes: ambos deveriam indicar a razão segundo a qual as vagas oferecidas estão resultando em mais pessoas com certificação superior.

\section{Análise crítica da TSG e da TCG}

Apesar do uso amplamente difundido da TSG e da TCG há mais de uma década, são muitas as críticas e questionamentos que recaem sobre esses indicadores. Alguns autores apontam que, para realizar a avaliação do desempenho das instituições, o TCU priorizou, sobretudo, o cálculo do custo, pouco preocupando-se em avaliar a qualidade da atividade acadêmica, o impacto e o retorno para a sociedade e para o indivíduo (FREIRE; CRISÓSTOMO; CASTRO, 2007; SILVA; MORGAN; COSTA, 2004).

A busca pela redução dos custos da educação superior é uma pauta globalmente influente e costuma estar relacionada ao projeto de modernização neoliberal (APPLE, 2001). Nesse contexto, o controle da evasão costuma estar atrelado à lógica da eficiência econômica, segundo a qual é necessário e suficiente formar mais pessoas com o menor investimento possível (sobretudo se essa formação ocorre nas instituições públicas de ensino superior). Por outro lado, as instituições de ensino e seus atores não são reféns da modernização neoliberal, mas podem, dentro de certos limites, ressignificar seus sentidos e resistir às suas intenções (BALL, 2006). O que se tem observado é que essas ressignificações recebem as influências dos problemas de construção da TCG e da TSG, entre os quais se destacam: (a) a anomalia da TCG/TSG; (b) o problema da contagem; (c) a retenção não contemplada. 
Passando em revisão à TCG e à TSG, percebem-se três razões pelas quais elas fazem injustiça às instituições de ensino. Uma análise mais cuidadosa revelará que essas taxas: (a) não medem o que dizem medir (por sofrerem variações mesmo quando o fluxo discente é preservado); (b) não são tão fidedignas quanto poderiam ser (contando casos de mobilidade estudantil como se fossem casos de evasão) e (c) ignoram a retenção, um elemento fundamental da trajetória discente.

\section{A anomalia da TSG e da TCG}

Um grave problema que um indicador pode sofrer é não medir o que pretende medir. Devido à maneira como a TSG e a TCG foram definidas, elas sempre sofrerão queda nos anos seguintes à expansão - mesmo se a probabilidade de conclusão do curso for mantida constante. As IES que expandiram sua oferta de vagas devem sentir uma queda substancial da TSG e da TCG nos anos seguintes à expansão.

Para compreender melhor essa anomalia, considere uma universidade fictícia que sempre tenha oferecido 100 vagas anuais e que forme sempre 75 alunos por ano. Para essa universidade, a TCG vale $75 \%$. Como, a cada 100 ingressantes, 75 se formam, é correto dizer que a probabilidade de conclusão do curso para esses alunos também é de 75\%. Agora, considere que, no ano de 2010, essa universidade tenha oferecido o dobro de vagas. Quando chegar ao ano de 2015, para manter a TCG em $75 \%$, a universidade deverá ter formado 150 alunos. O problema é que, tipicamente, os alunos ficam retidos no curso. Assim como seus veteranos, muitos dos que ingressaram em 2010 conseguirão terminar o curso somente seis, sete ou oito anos após o ingresso.

Como consequência, mesmo se a probabilidade de conclusão de curso permanecer em 75\%, os valores da TCG e da TSG devem experimentar uma queda após o quinto ano da expansão e essa queda poderá se prolongar por vários anos. Esse comportamento anômalo da TCG e da TSG será tão maior quanto mais ousado tiver sido o aumento da quantidade de vagas oferecidas. Portanto, a TCG e a TSG não são somente indicadores incapazes de medir o que declaram, mas prejudicam as instituições que mais ousadamente expandiram a quantidade de vagas oferecidas.

\section{O problema da contagem}

Outro problema presente no cálculo da TSG e da TCG diz respeito à forma como os estudantes são contados: usualmente são consideradas vagas, ingressos e matrículas, mas não os indivíduos propriamente ditos. Com a expansão e a diversificação da educação superior, é cada vez mais comum que alunos façam novo ingresso para 
mudar de curso ou de instituição. Cada vez mais, a evasão do curso não é evasão propriamente dita, mas mobilidade. Uma forma de dar conta das trajetórias cada vez mais complexas realizadas pelos alunos é acompanhá-los pelo número de seu cadastro de pessoa física (CPF), em uma abordagem longitudinal.

Por exemplo, considere o caso de um aluno que tenha iniciado três cursos de graduação ao longo de seu percurso acadêmico, completando somente o último. A cada curso que abandona, ele é contado como um caso de evasão, pois uma vaga foi ocupada sem gerar diploma. Quando, após algum tempo, esse aluno reingressa, passa a contar como indivíduo diferente. Nessa situação, o tempo de universidade do aluno também é reiniciado, como se ele estivesse ingressando pela primeira vez.

Um dos resultados dessas transições é que o público efetivamente atendido pelas IES é menos numeroso que a quantidade de novas matrículas efetivadas: a educação superior tem seus fregueses recorrentes. Na Universidade de Brasília, por exemplo, o número de novas matrículas efetivadas de 2002 a 2008 é 12\% superior ao número de pessoas físicas distintas (identificadas pelo CPF). Ou seja, não são poucos os casos de reingresso na educação superior. Isso indica que contar matrículas novas ou vagas oferecidas - tal como fazem a TCG e a TSG - introduz um viés superior a $10 \%$ nos indicadores. Corrigir a contagem por matrícula significaria, portanto, um refinamento importante dos indicadores de trajetória.

\section{A retenção não contemplada}

Apesar da importância da retenção, essa informação não está devidamente contemplada na TCG nem na TSG. Indicadores de retenção são potencialmente mais sensíveis aos problemas que podem ser resolvidos pela própria instituição, tais como as oportunidades de aprendizagem dadas aos alunos, a oferta de disciplinas, a concepção curricular dos cursos, o acolhimento da diversidade, entre outros.

Em vista da expansão do sistema de educação superior, as IES estão recebendo um público mais diversificado (sobretudo filhos de famílias que jamais foram à universidade). A maneira como a universidade (não) acolhe esses novos públicos pode ter impacto nos indicadores de retenção, mas nem sempre tem impacto na evasão. Por exemplo, no Instituto de Física da Universidade Federal do Rio Grande do Sul (UFRGS), identificou-se que a evasão atinge todos os estratos sociais proporcionalmente, mas a retenção distingue os mais privilegiados. Filhos de família com renda mais elevada e filhos de pais graduados e pós-graduados ficam retidos por menos tempo, enquanto os filhos de classe popular demoram mais tempo para concluir o curso (LIMA JUNIOR; OSTERMANN; REZENDE, 2012). Em um estudo ainda não publicado sobre os alunos da UnB, identificou-se 
que nenhuma das variáveis socioeconômicas disponíveis (eg., cor, renda familiar, escolaridade dos pais) tem poder preditivo sobre a evasão, que pode ser considerada um indicador menos sensível à origem social.

Na Universidade Federal do Espírito Santo (UFES), detectou-se relação significativa entre a retenção e um conjunto diversificado de 21 indicadores (PEREIRA et al., 2015). Entre eles, encontram-se descritores pessoais e familiares anteriores ao ingresso no curso tão bem como informações sobre o ambiente institucional e desempenho acadêmico dos alunos. Todas essas relações reforçam a hipótese de que a retenção é um indicador particularmente sensível tanto do ponto de vista da origem social dos sujeitos quanto das suas experiências de aprendizagem na universidade.

\section{A proposta de dois novos indicadores}

Em resposta aos problemas levantados aqui, este trabalho propõe dois novos indicadores da trajetória discente: a Taxa Longitudinal de Evasão (TLE) e a Taxa Longitudinal de Retenção (TLR). Característica fundante desses indicadores é sua natureza longitudinal, decorrente do acompanhamento da trajetória acadêmica do estudante por meio do seu CPF ao longo do tempo. Ou seja, o CPF dos estudantes deve ser utilizado como identificador primário na base de dados (em vez do número de matrícula ou registro adotado pela IES). A rigor, a contagem por CPF permite saber que as estatísticas obtidas descrevem as trajetórias efetivamente realizadas por cada estudante, e não as trajetórias virtuais dos números de matrícula.

Os dois indicadores, a TLE e a TLR, foram implementados com dados longitudinais do registro acadêmico dos estudantes da Universidade de Brasília, que tem, desde o ano 2002, a informação do CPF dos estudantes disponível. A partir do registro acadêmico dessa universidade, foi construído um algoritmo que permitiu elaborar automaticamente 243 relatórios individualizados por unidades acadêmicas, cursos e opções de curso.

\section{Da análise longitudinal}

O cálculo da TCG/TSG não envolve, de fato, uma análise longitudinal ${ }^{1}$, pois os estudantes formados hoje não são, necessariamente, os mesmos que ocuparam as vagas oferecidas cinco anos atrás. Por definição, uma análise longitudinal requer acompanhar os estudantes ao longo de um tempo prolongado e observar os percursos efetivamente realizados por eles. Portanto, uma análise dessa natureza requer definir um tempo de acompanhamento ao longo do qual se coletam as informações necessárias para levantar o destino final dos alunos.

\footnotetext{
Os estudos do tipo longitudinal são aqueles em que uma mesma amostra de participantes é acompanhada e avaliada ao longo do tempo (GUBA; LINCOLN, 1989).
} 
A unidade de observação em uma análise longitudinal é tipicamente uma coorte - um grupo de pessoas que compartilham um evento ocorrido no mesmo período. Neste estudo, utiliza-se o ano de ingresso para delimitar cada coorte. Assim, a coorte de 2002 refere-se ao conjunto de pessoas físicas que ingressaram na universidade, pela primeira vez, no ano de 2002. Uma vez delimitada, a coorte precisa ser acompanhada ao longo de um tempo suficiente para que a informação desejada esteja disponível. A saber: (1) status final (evadido ou diplomado), para cálculo da TLE; e (2) tempo de permanência, para cálculo da TLR.

Considere, por exemplo, a coorte de 2002 (cf. Gráfico 2). A fração de pessoas que ingressaram (pela primeira vez) na Universidade em 2002 e que ainda tinham vínculo ativo em 2016 é praticamente nula - ou seja, sabe-se o status final e o tempo de permanência de praticamente todos esses alunos. Por outro lado, entre os alunos com ingresso em 2012, aproximadamente $75 \%$ ainda tinham vínculo ativo no ano de 2016, época em que os dados foram extraídos. Ou seja, o futuro desses alunos na universidade ainda será indefinido. Para as coortes nessa situação, o acompanhamento longitudinal não produzirá informações confiáveis.

Para manter um erro de até 5\% nos indicadores, foram consideradas somente as coortes que ingressaram pela primeira vez na UnB há 8 anos ou mais, contados da época em que os dados foram extraídos (2016). Importante ressaltar que esse tempo mínimo de acompanhamento não é um valor universal, mas depende da própria universidade e da margem de erro que o analista considera aceitável.

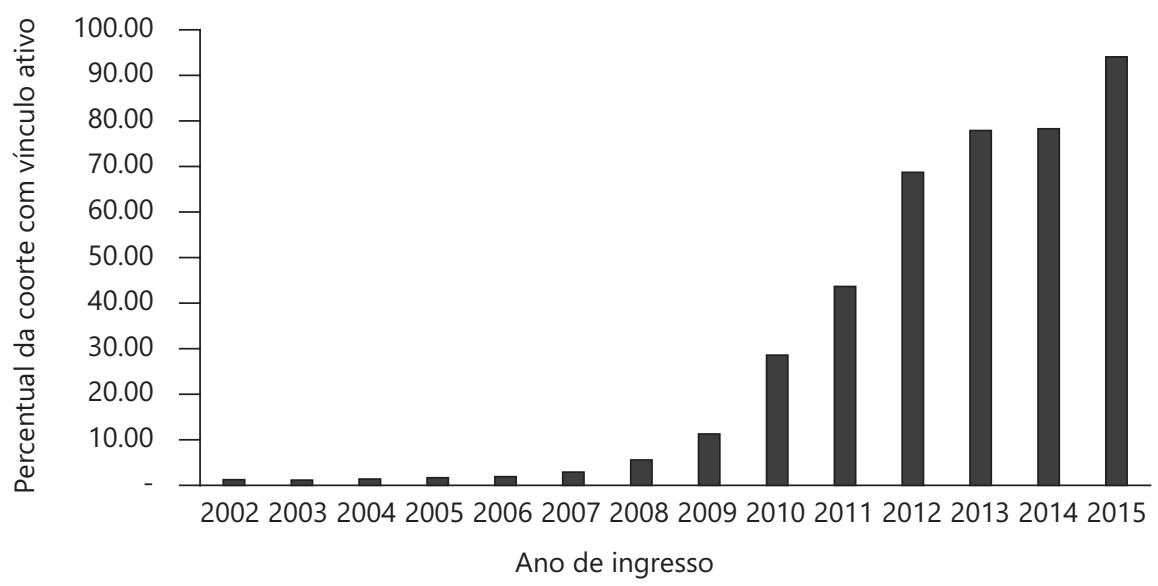

Gráfico 2. Percentual da coorte com vínculo ativo em 2016 em função do ano de ingresso. Fonte: elaborado pelos autores (2017). 


\section{Da preparação da base de dados}

O passo mais importante para a elaboração desses indicadores é a preparação da planilha. Nessa etapa, é preciso construir uma tabela em que o identificador primário seja o CPF. Isso acarreta a tomada de algumas decisões importantes. Por exemplo, considere que João tenha abandonado o curso de Física após três anos de seu ingresso, permanecendo fora da Universidade durante o ano seguinte. Em seguida, foi aprovado para o curso de Engenharia, no qual permaneceu por mais cinco anos até obter o diploma. Após sua formatura, João ingressou no curso de Ciências Sociais, abandonando-o em dois anos.

No Sistema de Graduação, onde os registros são armazenados, João tem duas matrículas abandonadas e somente uma concluída com formatura. Que critérios podem ser utilizados para condensar as informações desse aluno em um único registro que represente, da melhor maneira possível, a sua trajetória na universidade? Deve-se considerar como um caso de formatura ou de abandono? Por quanto tempo deverá ser considerado que ele permaneceu na universidade?

Pensando problemas dessa natureza, foram adotadas as seguintes regras no modelo:

(1) Considera-se que a universidade cumpriu o seu papel quando seus alunos se formam pelo menos uma vez - ou seja, informações referentes aos reingressos posteriores à primeira formatura foram ignoradas;

(2) Quando um aluno abandona um curso em favor de outro, seu tempo de permanência no curso anterior deve ser somado ao tempo total de permanência na instituição até porque é possível se beneficiar do aprendizado adquirido no primeiro curso para acelerar a formatura no segundo.

Portanto, no caso de João, seriam retidas somente as seguintes informações: ele ingressou no curso Física e, após oito anos, formou-se Engenheiro. João não é um caso de evasão da instituição, mas um caso de retenção.

\section{Taxa Longitudinal de Evasão (TLE)}

A Taxa Longitudinal de Evasão $\operatorname{TLE}(p, q)$ é definida como o percentual das pessoas físicas que, tendo ingressado no ano $q$, não obtiveram diploma até o ano de observação $p$. Assim, a TLE pode ser definida pela equação: 
$T L E(p, q)=\frac{\text { Quantidade de alunos sem diploma no ano p entre os que ingressaram no ano } q}{\text { Quantidade de alunos que ingressaram no ano } q}$,

em que $p$ é o ano de observação (ano em que os dados foram coletados) e $q$ é o ano de ingresso da coorte que está sendo acompanhada. Os valores $p$ e $q$ são escolhidos tal que $p-q$ seja igual ou superior ao tempo de acompanhamento necessário para que quase a totalidade dos alunos que ingressaram no ano $q$ tenham concluído ou abandonado o curso. No caso da UnB, essa diferença deve satisfazer $p-q \geq 8$ anos, com o propósito de garantir que a incerteza sobre a TLE não seja significativamente superior a 5\%. Assim, dado o ano de coleta dos dados $(p=2016)$, foram considerados somente os alunos com ingresso até o ano de $2008(q \leq 2008)$.

Da maneira como está formulado, o indicador TLE permite responder à seguinte pergunta: no universo dos estudantes que ingressaram na IES no ano $q$, quantos não obtiveram diploma? Usando dados do registro acadêmico da UnB, foi possível estimar os valores assumidos pela $\operatorname{TLE}(p, q)$ para as coortes com ingresso entre 2002 e 2008, conforme resultados apresentados na Tabela 1.

Como é possível perceber a partir da Tabela 1, a Taxa Longitudinal de Evasão apresenta uma sensível tendência de aumento ao longo do tempo no período observado. Entre os alunos que ingressaram nos anos de 2002 e 2003, menos de $20 \%$ saíram sem diploma. Já entre os que ingressaram a partir de 2006, observa-se aumento da evasão em $5 \%$ ou mais. Esse aumento não pode ser explicado por causa da presença de mais pessoas com vínculo ativo nas coortes mais jovens.

Tabela 1. Dados referentes à Taxa Longitudinal de Evasão $\operatorname{TLE}(p, q)$ na UnB no ano de observação $p=2016$ referente aos anos de ingresso de 2002 a 2008.

\begin{tabular}{lcccc}
\hline $\begin{array}{l}\text { Ano } \boldsymbol{q} \text { de } \\
\text { ingresso da } \\
\text { coorte }\end{array}$ & $\begin{array}{c}\text { Alunos que } \\
\text { ingressaram } \\
\text { no ano } \mathbf{q}\end{array}$ & $\begin{array}{c}\text { Alunos sem diploma } \\
\text { em 2016 entre os } \\
\text { que ingressaram no } \\
\text { ano } \mathbf{q}\end{array}$ & $\begin{array}{c}\text { \% ingressantes } \\
\text { no ano } \mathbf{q} \text { com } \\
\text { vínculo ativo em } \\
\mathbf{2 0 1 6}\end{array}$ & TLE (2016, q) \\
\hline 2002 & 3442 & 667 & $1,23 \%$ & $19,4 \%$ \\
2003 & 3534 & 690 & $1,17 \%$ & $19,5 \%$ \\
2004 & 3658 & 774 & $1,37 \%$ & $21,2 \%$ \\
2005 & 3624 & 743 & $1,67 \%$ & $20,5 \%$ \\
2006 & 4318 & 1070 & $1,87 \%$ & $24,8 \%$ \\
2007 & 6080 & 1709 & $2,93 \%$ & $28,1 \%$ \\
2008 & 5235 & 1494 & $5,56 \%$ & $28,5 \%$ \\
\hline
\end{tabular}

Fonte: autores (2016). 


\section{Taxa Longitudinal de Retenção (TLR)}

A Taxa Longitudinal de Retenção $\operatorname{TLR}(p, q)$ é definida como o percentual das pessoas físicas que, tendo ingressado no ano $q$ e se formado até o ano de observação $p$, obtiveram diploma fora do prazo previsto para o curso. Portanto, a TLR pode ser definida pela equação:

$\operatorname{TLR}(p, q)=\frac{\text { Quantidade de alunos formados fora do prazo até o ano } p \text { entre os que ingressaram no ano } q}{\text { Quantidade de alunos formados até o ano } p \text { entre os que ingressaram no ano } q}$,

em que $p$ é o ano de observação (ano em que os dados foram coletados) e $q$ é o ano de ingresso da coorte que está sendo acompanhada. São considerados formados fora do prazo os alunos cujo tempo de permanência na universidade ultrapassa a duração padrão prevista para o curso no qual o aluno se formou.

A TLR permite responder à seguinte pergunta: no universo dos estudantes que ingressaram no ano $q$ e se formaram, quantos ficaram retidos no curso por tempo superior ao previsto? Cumpre destacar também que a TLR pode ser obtida por meio de uma aplicação da análise de sobrevivência (COLOSIMO; GIOLO, 2006) aos estudantes que obtiveram diploma de graduação na IES. Usando dados do registro acadêmico da UnB, foi possível estimar os valores assumidos pela $\operatorname{TLR}(p, q)$ para as coortes com ingresso entre 2002 e 2008, conforme resultados apresentados na Tabela 2 .

Tabela 2. Dados referentes à Taxa Longitudinal de Retenção $\operatorname{TL} R(p, q)$ na UnB no ano de observação $p=2016$ referente aos anos de ingresso de 2002 a 2008.

\begin{tabular}{lcccc}
\hline $\begin{array}{l}\text { Ano } \boldsymbol{q} \text { de } \\
\text { ingresso da } \\
\text { coorte }\end{array}$ & $\begin{array}{c}\text { Alunos } \\
\text { formados até } \\
\mathbf{2 0 1 6} \text { entre os } \\
\text { que ingressaram } \\
\text { no ano } \boldsymbol{q}\end{array}$ & $\begin{array}{c}\text { Alunos formados } \\
\text { fora do prazo } \\
\text { entre os que } \\
\text { ingressaram no } \\
\text { ano } \mathbf{q}\end{array}$ & $\begin{array}{c}\text { \% ingressantes } \\
\text { no ano } \mathbf{q} \text { com } \\
\text { vínculo ativo em } \\
\mathbf{2 0 1 6}\end{array}$ & TLR (2016, q) \\
\hline 2002 & 2775 & 1807 & $1,23 \%$ & $65,1 \%$ \\
2003 & 2844 & 1885 & $1,17 \%$ & $66,3 \%$ \\
2004 & 2884 & 1876 & $1,37 \%$ & $65,0 \%$ \\
2005 & 2881 & 1777 & $1,67 \%$ & $61,7 \%$ \\
2006 & 3248 & 2035 & $1,87 \%$ & $62,7 \%$ \\
2007 & 4371 & 2388 & $2,93 \%$ & $54,6 \%$ \\
2008 & 3741 & 2147 & $5,56 \%$ & $57,4 \%$ \\
\hline
\end{tabular}

Fonte: elaborada pelos autores (2017). 
Como é possível perceber a partir da Tabela 2, a TLR da UnB apresenta uma tendência de queda ao longo do tempo. Entre os alunos diplomados das coortes de 2002 a 2004, aproximadamente $65 \%$ não conseguiram concluir o curso no prazo de integralização curricular previsto. Nos anos de 2007 e 2008, a taxa de retenção caiu pouco abaixo de $60 \%$. Integrando as informações das Tabelas 1 e 2, é possível observar que a retenção diminuiu no mesmo período em que a evasão aumentou. Essa redução da retenção também não pode ser explicada por haver mais alunos com vínculo ativo entre as coortes mais jovens. Deve resultar, portanto de uma mudança gradual no comportamento de conjunto do fluxo de alunos na instituição.

Assim como ocorre com a TLE, é recomendável agrupar os alunos com ingresso entre 2002 e 2008 para estimar o valor da TLR nos cursos de graduação. Nesse agrupamento, a TLR média de toda a universidade ficou em $61,2 \%$, ou seja, somente quatro em cada dez alunos formados das coortes de 2002 a 2008 obtiveram seus diplomas no prazo previsto.

\section{Considerações Finais}

Como resposta às limitações das taxas empregadas pelo MEC e pelo TCU para avaliar o fluxo discente nas IES, foram propostas aqui duas alternativas: a Taxa Longitudinal de Evasão (TLE) e a Taxa Longitudinal de Retenção (TLR). Ao longo do artigo, elencaram-se razões pelas quais essas taxas refletem com mais fidedignidade os fluxos reais de trajetória acadêmica dos estudantes de graduação nas IES, o que corresponde à questão de pesquisa original deste trabalho: de que maneira a TLE e a TLR podem contribuir para a compreensão das trajetórias discentes nos cursos de graduação?

Como foi discutido ao longo do texto, as taxas propostas resolvem limitações dos indicadores vigentes com algumas vantagens. A principal é possibilitar um olhar diferente sobre a relação entre evasão e mobilidade. Afinal, uma parte do que se tem identificado por evasão

não é exclusão mas mobilidade, não é fuga, mas busca, não é desperdício mas investimento, não é fracasso - nem do aluno nem do professor, nem do curso ou da instituição - mas tentativa de buscar o sucesso ou a felicidade, aproveitando as revelações que o processo natural de crescimento dos indivíduos faz sobre suas reais potencialidades (RISTOFF, 1995 p. 56). 
Recentemente, a consultoria legislativa da Câmara dos Deputados (GILIOLI, 2016) mostrou preocupação com os impactos do Sistema de Seleção Unificado (SiSU) nas taxas de evasão da educação superior. De fato, ao democratizar o ingresso e promover a mobilidade estudantil, o SiSU tem contribuído também para que estudantes abandonem um curso em favor de outro de sua preferência ou uma instituição em favor de outra por motivos diversos. Assim, para os analistas que não buscam perceber os sujeitos por trás das estatísticas, o SiSU pode ser considerado uma política problemática por contribuir para a evasão dos cursos de graduação. Talvez o que falte agora seja ressignificar o conceito de evasão, reconhecendo que ela pode ser produzida por razões tão variadas que não faz sentido torná-la um problema a priori. Mais importante que saber quantos alunos desistiram de concluir o curso que iniciaram, é saber para onde foram e por que razões o fizeram.

No estudo aqui apresentado, observou-se que o número de novas matrículas efetivadas de 2002 a 2008 é $12 \%$ superior ao número de pessoas físicas distintas (identificadas pelo CPF). Isso indica que uma quantidade expressiva dos casos registrados de evasão até então na UnB representa, na verdade, mobilidade entre cursos da mesma instituição. Com dados nacionais, seriam obtidos resultados ainda mais impressionantes, acompanhando a trajetória dos alunos entre diferentes IES por meio do seu CPF. Em tempos de aumento progressivo da mobilidade dos cidadãos, que estão cada vez menos vinculados ao seu território de origem e, com alguma facilidade, mudam de curso, de instituição ou de município, estatísticas longitudinais vão se tornando uma necessidade.

Outra análise de dados referentes à Universidade de Brasília revelou também que a renda média dos alunos que abandonam voluntariamente o curso costuma ser semelhante à renda média daqueles que o concluem (UNB, 2015). Em um primeiro momento, isso pode causar estranheza, mas, novamente, a surpresa vem de se ter presumido que a evasão emerge necessariamente em situações de fracasso escolar, vulnerabilidade social e negligência da instituição: existem estudantes que abandonam seus cursos (ou a educação superior) em favor de um futuro profissional considerado por eles como mais vantajoso e que não dependeria da obtenção de um diploma de graduação para ser realizado.

Na educação básica, o abandono está geralmente relacionado ao fracasso escolar e à vulnerabilidade social. Por isso, faz sentido tratar a evasão como um processo de auto-eliminação, inserindo-a em um tipo de crítica social da escola. Já na educação superior, não é raro que alunos abandonem seus cursos em favor de uma trajetória profissional objetivamente mais vantajosa de tal maneira que a 
relação esperada entre evasão e vulnerabilidade social nem sempre se observa. Os indicadores de retenção, por outro lado, parecem ser mais sensíveis ao fracasso escolar e à origem social dos alunos. Por isso, têm maior potencial para indicar a medida com que as IES falham em incluir efetivamente seus alunos de origem social menos favorecida.

Enfim, há razões para perceber que, fora da pauta econômica, não há por que tomar as taxas evasão, de per si (inclusive a taxa longitudinal proposta aqui), como indicadoras de sucesso ou fracasso dos cursos de graduação. Não basta saber quantos alunos abandonam a graduação; é preciso compreender suas razões de maneira a perceber os limites da responsabilidade institucional. A literatura sobre a educação superior dá indicativos de quais seriam as razões que levam os alunos a desistir. O estudo aqui apresentado concentrou-se na construção das taxas TLE e TLR e na sua comparação com outros indicadores, havendo necessidade de se fazer uma análise mais abrangente em outra oportunidade.

O fato desses indicadores dependerem da informação do CPF pode ser uma limitação para a realização dos estudos em outras IES. Porém, superado esse entrave, a metodologia apresentada aqui pode ser empregada para especificar o perfil socioeconômico do aluno que abandona assim como o perfil curricular dos cursos em que a desistência é maior. Esses indicadores também possibilitam uma análise aprofundada da mobilidade acadêmica, podendo ser determinados os cursos que mais doam alunos para outros cursos bem como aqueles que mais recebem estudantes. 


\title{
Longitudinal dropout and evasion rates: a methodology for studying the trajectory of students in higher education
}

\begin{abstract}
With the expansion of the higher education system, dropout and retention have been rediscovered by educational research. In this paper, we critically evaluate the rates used by the Brazilian MEC (Ministry of Education) and TCU (Court of Accounts) to control and follow students' trajectory through universities. Drawing on this critique, alternative indicators are presented to quantify dropout and retention: the longitudinal dropout rate $(L D R)$ and the longitudinal retention rate (LRR). These indicators were tested with data extracted from the academic record of Universidade de Brasilia (UnB). The results indicate progressive increase in dropout and reduced retention. These transformations may be related to the process of expansion of the education system itself.
\end{abstract}

Keywords: Dropout. Retention. Higher education.

\section{Tasas Longitudinales de Retención y Evasión: una metodología para estudio de la trayectoria de los estudiantes en la educación superior}

\section{Resumen}

Con la expansión del sistema federal de educación superior, la evasión y la retención han sido redescubiertas por la investigación educativa. En este artículo, se evalúan críticamente las tasas empleadas por el Ministerio de Educación (MEC) y el Tribunal de Cuentas de la Unión (TCU) para control y acompañamiento de la trayectoria de los alumnos en las universidades brasileñas. A partir de esta crítica, se proponen indicadores alternativos para cuantificar la evasión y la retención: la tasa longitudinal de evasión (TLE) y la tasa longitudinal de retención (TLR). Estos indicadores se probaron con datos extraídos del registro académico de la Universidad de Brasilia (UnB). Los resultados de esa institución indican, progresivamente, el aumento de la evasión y reducción de la retención. Estas transformaciones pueden estar relacionadas con el propio proceso de expansión del sistema educativo.

Palabras clave: Evasión. Retención. Educación superior. 


\section{Referências}

ALFA-GUIA, P. Hacia la construcción colectiva de un marco conceptual para analizar, predecir, evaluar y atender el abandono estudiantil en la educación superior. [s.l: s.n.], 2013. Disponível em: <http://www.alfaguia.org/www-alfa/ index.php/es/>. Acesso em: 18 dez. 2018.

ANDIFES. Diplomação, retenção e evasão nos cursos de graduação em instituições de ensino superior públicas. Brasília, DF: ANDIFES/ABRUEM/ $\mathrm{SESu} / \mathrm{MEC}, 1996$.

ANDRIOLA, W. B.; ARAUJO, A. C.. Uso de indicadores para diagnóstico situacional de Instituições de Ensino Superior. Ensaio: Avaliação de Políticas Públicas de Educação, v. 26, n. 100, p. 645-663, jul./set. 2018. https://doi.org/10.1590/s0104-40362018002601062

APPIO, J. et al. Atributos de permanência de alunos em instituição pública de ensino superior. G. U. A. L., v. 9, n. 2, p. 216-37, 2016. https://doi.org/10.5007/1983-4535.2016v9n2p216

APPLE, M. W. Reestruturação educativa e curricular e as agendas neoliberal e neoconservadora. Currículo sem Fronteiras, v. 1, p. 5-33, ene.-jun. 2001.

BAGGI, C. A. S.; LOPES, D. A. Evasão e avaliação institucional no ensino superior: uma discussão bibliográfica. Avaliação (Campinas), v. 16, n. 2, p. 355-74, 2011. https://doi.org/10.1590/S1414-40772011000200007

BALL, S. J. Education policy and social class. New York: Routledge, 2006.

BIGGERI, L.; BINI, M. Evaluation at university and state level in Italy: need for a system of evaluation and indicators. Tertiary Education and Management, v. 7, n. 2, p. 149-162, 2001. https://doi.org/10.1023/A:1011345632034

BRASIL. Decreto No 6.096, de 24 de abril de 1997. Institui o Programa de Apoio a Planos de Reestruturação e Expansão das Universidades Federais REUNI. Diário Oficial da União, 25 abr. 1997.

BRASIL. Lei N ${ }^{0} 13.005$, de 25 de junho de 2014. Aprova o Plano Nacional de Educação - PNE, e dá outras providências. Diário Oficial da União, 26 jun. 2014. 
BRASIL. Ministério da Educação e Cultura. Reuni: reestruturação e expansão das universidades federais. Brasília, DF: SESu, 2007.

BRASIL. Tribunal de Contas da União. Orientação para o cálculo dos indicadores de gestão. Decisão TCU n. 408/2002 - Plenário. 2005. Disponível em: <http://portal.mec.gov.br/sesu/arquivos/pdf/indicadores.pdf > Acesso em: 18 dez. 2018.

COLOSIMO, E. A.; GIOLO, S. R. Análise de sobrevivência aplicada. São Paulo: Edgard Blucher, 2006.

DUNDAR, H.; LEWIS, D. R. Equity, quality and efficiency effects of reform in Turkish higher education. Higher Education Policy, v. 12, n. 4, p. 343-66, Dec. 1999. https://doi.org/10.1016/S0952-8733(99)00016-1

FERRAO, M.E.; ALMEIDA, L.S. Multilevel modeling of persistence in higher education. Ensaio: Avaliação de Políticas Públicas de Educação, v. 26, n. 100, p. 664-83, jul./set. 2018. https://doi.org/10.1590/s010440362018002601610

FREIRE, F. S.; CRISÓSTOMO, V. L.; CASTRO, J. E. G. Análise do desempenho acadêmico e indicadores de gestão das IFES. Produção Online, v. 226, ed. esp,. p. 1-25, 2007. https://doi.org/10.14488/1676-1901.v7i4.57

GILIOLI, R. S. P. Evasão em instituições federais de ensino superior no Brasil: expansão da rede, SiSU e desafios. Brasília, DF: Câmara dos Deputados, 2016.

GUBA, E.; LINCOLN, Y. Fourth generation evaluation. Califórnia: Sage, 1989.

INEP - Instituto Nacional de Estudos e Pesquisas Educacionais Anisio Teixeira. Censo da educação superior 2013: resumo técnico. Brasília, DF: INEP, 2015.

LIMA, P. G. Políticas de educação superior no Brasil na primeira década do século XXI: alguns cenários e leituras. Avaliação (Campinas), v. 18, n. 1, p. 85-105, mar. 2013. https://doi.org/10.1590/S1414-40772013000100006

LIMA JUNIOR, P.; SILVEIRA, F. L. DA; OSTERMANN, F. Análise de sobrevivência aplicada ao estudo do fluxo escolar nos cursos de graduação em Física: um exemplo de uma universidade brasileira. Revista Brasileira de Ensino de Física, v. 34, n. 1, 1403, 2011. https://doi.org/10.1590/S1806-11172012000100014 
LÓPEZ SEGRERA, F. Educación superior comparada: tendencias mundiales y de América Latina y Caribe. Avaliação: Revista da Avaliação da Educação Superior (Campinas), v. 21, n. 1, p. 13-32, mar. 2016. https://doi.org/10.1590/S1414-40772016000100002

OCDE. Education at a glance 2014: highlights. Paris: OECD, 2014.

OCDE. Education at a glance 2016: OECD indicators. Paris: OECD, 2016.

PEREIRA, A. S. et al. Fatores relevantes no processo de permanência prolongada de discentes nos cursos de graduação presencial: um estudo na Universidade Federal do Espírito Santo. Ensaio: Avaliação e Políticas Públicas em Educação, v. 23, n. 89, p. 1015-39, 2015. https://doi.org/10.1590/S0104-40362015000400009

PRESTES, E. M. T; FIALHO, M. G. D. Evasão na educação superior e gestão institucional: o caso da Universidade Federal da Paraíba. Ensaio: Avaliação de Políticas Públicas de Educação, v. 26, n. 100, p. 869-89, 2018. https://doi.org/10.1590/s0104-40362018002601104

RISTOFF, D. Evasão: exclusão ou mobilidade. Florianópolis: UFSC, 1995.

SEGENREICH, S. C. D.; CASTANHEIRA, A. M. Expansão, privatização e diferenciação da educação superior no Brasil pós - LDBEN/96: evidências e tendências. Ensaio: Avaliação e Políticas Públicas em Educação, v. 17, n. 62, p. 55-86, 2009. https://doi.org/10.1590/S0104-40362009000100004

SILVA, C. A. T.; MORGAN, B. F.; COSTA, P. S. Desenvolvimento e aplicação de uma metodologia para cálculo do custo-aluno de instituições públicas de ensino superior: um estudo de caso. Revista de Administração Pública, v. 38, n. 2, p. 243-59, 2004.

SILVA, F. I. C.; RODRIGUES, J. D. P.; BRITO, A. K. A. Retenção escolar no curso de Educação Física da Universidade Federal do Piauí. Educação em Perspectiva, v. 5, n. 2, p. 75-96, jul./dez. 2014.

UNIVERSIDADE DE BRASÍLIA - UNB. Pesquisa de egressos da UnB na RAIS 2013. Brasília, DF, 2015.

UNESCO. Declaração mundial sobre a educação superior no século XXI: visão e ação. Paris, 1998. 
UNESCO. Conferência Mundial sobre Ensino Superior 2009: as novas dinâmicas do ensino superior e pesquisas para a mudança e o desenvolvimento social. Paris: UNESCO, 2009a.

UNESCO. Global education digest 2009: comparing education statistics across the world. Montreal, 2009b.

YONEZAWA, A. Quality assessment and assurance in japanese universities: the plight of the social sciences. Social Science Japan Journal, v. 11, n. 1, p. 69-82, Jul. 2008. https://doi.org/10.1093/ssjj/jyn021

\section{Informações dos autores}

Paulo Lima Junior: Doutor em Ensino de Física. Professor Adjunto e membro do Programa de Pós-Graduação em Educação em Ciências da Universidade de Brasília (UnB). Contato: paulolimajr@unb.br

Cynthia Bisinoto: Doutora em Psicologia. Professora Adjunta da Universidade de Brasília (UnB). Contato: cynthia@unb.br

Nilce Santos de Melo: Doutora em Patologia Bucal. Professora Associada e membro dos programas de pós-graduação em Ciências da Saúde e Odontologia da Universidade de Brasília (UnB).Contato: nilce@unb.br

Mauro Rabelo. Doutor em Matemática. Professor Associado e membro do mestrado profissional em matemática em rede nacional (PROFMAT) da Universidade de Brasília (UnB). Contato: rabelo@unb.br 